\title{
A framework for organisational operational response and strategic decision making for long term flood preparedness in urban areas
}

\author{
G. Coates ${ }^{1}$, G. I. Hawe ${ }^{1}$, M. McGuinness ${ }^{2}$, N. G. Wright ${ }^{3}$, \\ D. Guan ${ }^{3}$, T. Harries ${ }^{4} \&$ L. McEwen ${ }^{5}$ \\ ${ }^{1}$ Durham University, UK \\ ${ }^{2}$ University of Sheffield, $U K$ \\ ${ }^{3}$ University of Leeds, $U K$ \\ ${ }^{4}$ University of Kingston, $U K$ \\ ${ }^{5}$ University of the West of England, $U K$
}

\begin{abstract}
Recent years have seen flooding emerge as a significant risk facing United Kingdom (UK) businesses. This paper presents an overview of a framework aimed at improving such organisations' response to and preparedness for floods in urban areas, reducing the disruption and economic loss associated with flooding, and strengthening the flood resilience of the wider economy and society. To achieve these aims an understanding will be gained of business continuity processes and how private and public sector organisations behave and interact in the immediate aftermath of floods. Based on this understanding, agent based modelling and simulation will be used to identify factors which influence organisations' behaviours to flood response and preparedness, and thus determine ways of improving business continuity. Economic analyses will establish the local impacts of flooding in a range of UK urban areas and the cascading effects to the wider economy. Iterations of agent based simulations will enable analyses of how changes in behaviour could influence these impacts and better enable organisational operational response and inform strategic decision making for long term flood preparedness. Thus, practical guidance will be developed to inform organisations how to better adapt to flood risk through more effective business continuity planning, thereby increasing flood resilience.
\end{abstract} Keywords: floods, decision making, organisations, response and preparedness. 


\section{Introduction}

In recent years flooding has emerged as a significant endemic risk facing individuals and organisations across the UK. Indeed, the autumn and early winter of 2000-01 saw the worst flooding in the UK since 1947 and the 2007 floods resulted in the greatest loss of essential services since World War II. Flooding is characterised by high levels of uncertainty, unpredictability and emergence; key elements of hazards symptomatic of a 'risk society' [1,2]. Hazards such as modern day flooding require novel response and regulation [3], and urgently, given that milder wetter winters and localised extreme weather events are likely to be an ongoing feature of both national and global climate patterns [4-6].

In 2012, the UK's Engineering and Physical Sciences Research Council funded three major projects focussing on innovative solutions to flood risk. This paper presents an overview of a framework for one of those projects aimed at influencing the behaviours of businesses faced with urban flooding and flood risk. The framework aims to enable different types of organisation to enhance their strategic capabilities for both short term event response and longer term preparedness. Thus, organisations will be able to reduce the disruption and economic losses associated with flooding and, as a result, strengthen the flood resilience of both the wider economy and society. To achieve this aim, four integrated and interdisciplinary research goals are being pursued. Firstly, there is a need to achieve a better understanding of business continuity processes and how private and public sector organisations behave and interact with each other in the immediate and longer term aftermath of flood events. Secondly, there is a need to establish how agent based modelling and simulation can be used to improve organisational business continuity by means of representing attributes and simulating behaviours of different types of at-risk UK organisations and the consequences of these for both the short-term response to flooding and longerterm preparedness. Thirdly, there is a need to assess the impacts of flooding on economic systems both within and beyond the immediately affected urban area and explore how changes in organisational behaviour could influence these impacts. Fourthly, there is a need to develop innovative approaches to the promotion of organisational behaviour change and adaptive organisational learning throughout the flood cycle. In pursuing each of these four goals, the research exploits synergies between the academic fields of organisational business continuity management, agent based modelling and simulation, disaster management, emergency planning, flood modelling and prediction, economic modelling and the social/behavioural sciences.

\section{Background}

It has been estimated that flood damage could account for $£ 10 \mathrm{bn}$ to the UK economy in 25 years [7] and that risks relating to precipitation, over the next 30 100 years, will increase by 2 to 4 times across the UK, with some locations experiencing changes beyond this range [8]. A key recommendation emerging from the formal review of the 2007 UK floods was the need to reduce the risk of 
flooding and its impact [5]. The UK's National Security Strategy [9] discusses the importance of flexibility and resilience to natural and man-made disasters, but also emphasises working in alliances and partnerships to build corporate and community resilience. This can be best understood as part of a paradigm shift in approaches to the management of risk itself. Policy developments in the UK which address risk and resilience are increasingly underpinned by concepts such as communal risk reduction and also, through the involvement of a range of nonstate bodies, risk spreading [10]. One powerful stakeholder is the insurance industry. The cost to insurers of the 2007 UK floods alone was $£ 3$ bn. Insurers have stated that losses on this scale are not sustainable for the insurance industry. Currently, under a pan-industry agreement with government, expiring mid 2013, British insurers are obliged to make insurance cover for flood as widely available as possible and, in effect, insure properties that would otherwise be deemed uninsurable [11]. It is probable that insurance coverage for flood risk will become less available and more expensive after 2013. The impact of this on organisations, and particularly Small and Medium Enterprises (SMEs) and third sector bodies, is significant given that SMEs account for over $50 \%$ of UK employment and gross domestic product. However, in light of the paradigm shift outlined, and in the context of the current fiscal crisis, it is unlikely that government will wholly absorb the risk and associated costs. Rather, it is likely that there will be an even greater emphasis upon risk spreading as a means for building resilient cities and communities. Citizens, private sector organisations and public sector bodies will increasingly be obliged to engage in the management of flood risk and the creation of resilience at the local community, regional and national level. Organisational and local resilience are vital interacting components of an overarching strategy for national resilience.

\section{Related work}

Research on the response to major natural and man-made events has focussed primarily on 'category 1' responders [12]. However, there is a dearth of research on the response of business organisations faced with major disruption caused by flooding. Effective response to disruption through preparedness can mitigate the impact of a major flood event on organisations. This approach forms a cornerstone of business continuity management [13], which is recognised as an important tool for organisational survival in the face of disruption $[14,15]$. Effective business continuity can reduce organisational down-time and facilitate a more rapid return to normality thereby lessening the economic impact at the level of the organisation and beyond. Previous reviews have highlighted the role of business continuity as part of any successful flood response [5]. Despite this, in the UK, organisational engagement with business continuity remains low with less take-up by SMEs and third sector organisations relative to larger businesses and public sector bodies $[16,17]$. There are indications that a lack of resources and capabilities may account for this lower take-up, however no systematic investigation has yet been undertaken. 
Whilst agent based models (ABMs) have provided useful insights into emergency responses to major events $[18,19]$, their focus to date has been on agents representing individuals exhibiting behaviour intended to mimic emergency responders or members of the public. In flood management, ABMs have been used to model evacuation strategies, albeit without agents representing emergency service personnel $[20,21]$. In the response to flood events, there exists scope to develop and utilise $\mathrm{ABMs}$ by representing and modelling organisations, rather than individuals, as agents and considering timeframes beyond immediately after the event occurs. ABMs offer an opportunity for using and embedding iterative stakeholder learning and feedback within the modelling process. This can occur through organisation engagement with model outputs from agent based simulations of past or future flood events based on historical data and/or predictions from flood modelling. Indeed, predictions from flood modelling can complement incomplete observed data for specific events [22, 23], postulate future scenarios based on organisation agent behaviour, and provide flooding frequencies [24]. Feedback on behaviour changes, gained from working with stakeholder organisations, can then be fed back into further simulations of the ABM, so improving modelling of the impact of changes in organisations' preparation for and response to flood hazards. In the context of organisational response, organisational agents include SMEs, the emergency services and emergency planning units, local authorities and the Environment Agency.

\section{Framework}

The framework, presented in Figure 1, aims to iteratively evaluate organisations' response strategies to flooding in order to develop guidelines and recommendations to influence behaviour change enabling them to better prepare for future floods and adapt to flood risk through more effective continuity planning.

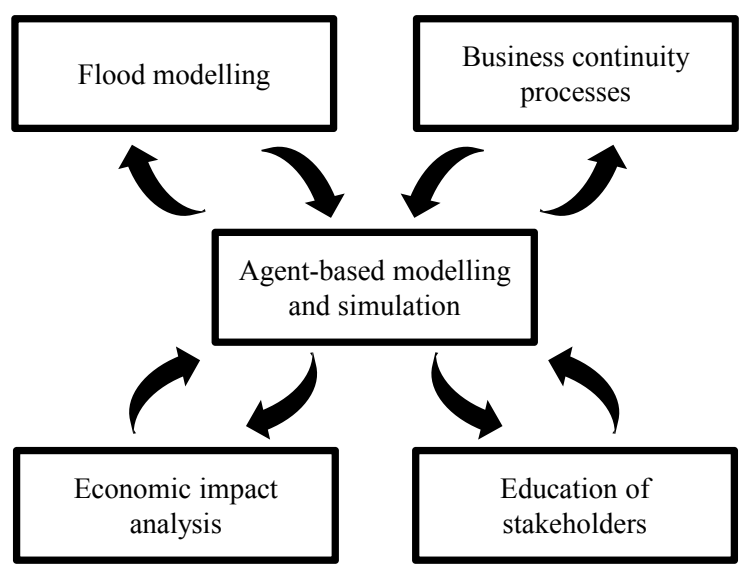

Figure 1: $\quad$ Integrated framework. 
This aim will be brought about through the integrated application of flood modelling with agent based modelling and simulation of organisations informed by business continuity processes, analysis of the economic impacts radiating out from directly flood-affected areas, and the education of stakeholders in better preparing for flood events.

\subsection{Flood modelling and organisational level agent based modelling and simulation}

The focus of this strand of the research is to develop an agent based approach to model and simulate organisational behaviour in the face of flood events. This involves the representation of organisations' attributes and behaviour in terms of their actions and interactions in response to flood events, thus informing strategic decision making for longer term preparedness. A range of private businesses and public organisations will be represented varying in size, sector and operational behaviour. Prior to simulations of organisational behaviour in terms of responding to and preparing for flood events, flood inundation modelling coupled with historical data will be used in a complementary manner to provide detailed information to the $\mathrm{ABM}$ regarding which organisation agents are affected. Inundation modelling is necessary to complete what is usually incomplete data from historical records, or where there are no data in cases lacking recent records. The virtual geographical environment component of the $\mathrm{ABM}$, developed using OS MasterMap, is fed information regarding an inundation prediction thus allowing flood events to be modelled in any urban area of the UK, even those areas not yet exposed to flooding. As a result, all organisations in this area directly and indirectly affected by a flood event can be identified. An example geographical area affected by a flood event is shown in Figure 1.

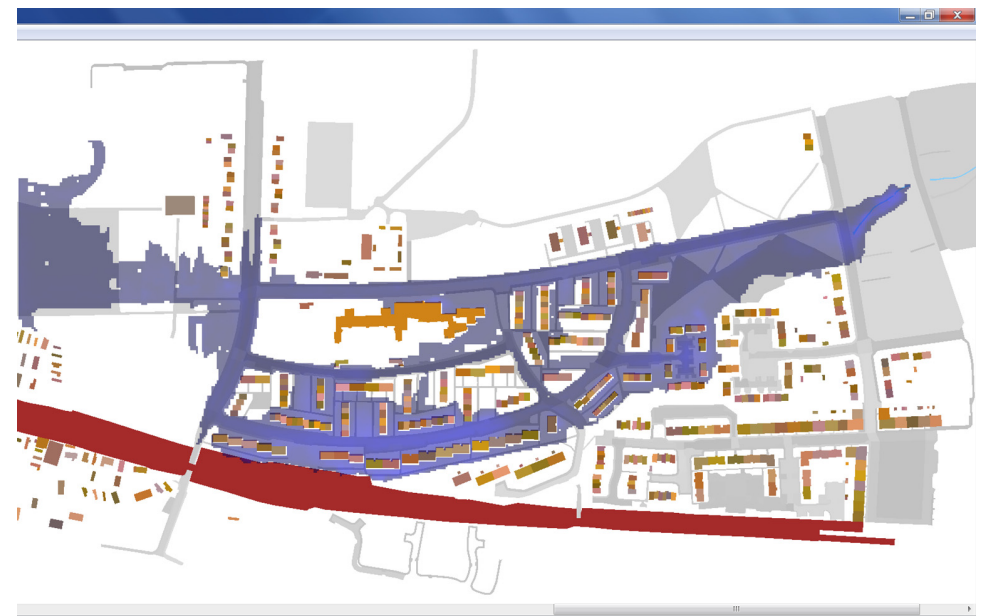

Figure 2: Example geographical area affected by a flood event. 
Within the affected geographical area, intelligent agents are used to model the various types of private and public sector organisations with each having different attributes and rules governing their operational behaviour in terms of actions and interactions with other organisations and communities. In addition to the virtual geographic environment illustrated in Figure 1, an agent interaction framework will capture, in simulations of floods events and the aftermath, the interdependent behavioural actions of organisations and their impact. Multiple simulations reflecting varying levels of uncertainties will be performed in two stages to gain an understanding of the dynamic complexity of organisations' interactions in the aftermath of a flood: (a) simulations in the context of their short term and longer term response to flood events thus informing changed behaviour for preparedness; (b) simulations of their short term response with changed behaviour for preparedness measures adopted in light of the simulations in (a) and output from economic modelling to evaluate the effect of such measures and inform the education of stakeholders.

\subsection{Business continuity processes}

This strand of the research is aimed at gaining an understanding of businesses' response to flood events within a local, regional and national context in the short and longer term in order to generate insights and data on the attributes, dynamic behaviour and interactions of organisations. These insights and data will form the basis of the attributes and rules governing the operational behaviour of private and public businesses represented in the ABM mentioned in Section 4.1. To achieve this aim, this research strand will explore the factors which underpin both effective and ineffective organisational response to flooding by identifying what, why and when organisations behave in particular ways in the flood response and preparedness phases. This will involve examining how long it takes organisations to move through the response phase (short term) and preparedness phase (longer term) and regain normal operational functioning so that a better understanding can be gained of what constitutes short term and longer term with respect to effective flood risk. Organisational behaviours are influenced directly and indirectly through interactions with a range of other stakeholders such as the emergency services, local authorities, quasi-governmental agencies, insurers, local community and other organisations, for example across supply and distribution chains. Consequently, it is not possible to generate meaningful insights into these behaviours without contextualizing these actions dynamically within this broader network of actors/agents. By taking this holistic perspective, it is possible to identify what barriers may exist to effective business continuity and where these barriers lie, for example at the micro or meta level. To generate robust and rich data, a multi-method approach is being taken through integrating traditional methods of data collections, such as interviews and focus groups, with data captured from new technology for a number of flood event case studies. Importantly, case studies being considered vary in terms of severity as well as flooding source such as pluvial, fluvial and coastal. As mentioned earlier, data generated will feed into the ABM to enable the simulation of organisational behaviour. Subsequent changes in actions and behaviours will then be 
interrogated iteratively in the context of the research framework, as well as directly with stakeholders through appropriate means such as follow-up interviews and online forums, blogs and wikis.

\subsection{Impact of flooding to urban economy and wider economic systems}

The emphasis of this research strand is the economic analysis of the impact of flood events, which is central to identifying economic vulnerabilities and thus where preparedness measures are best applied. Assessments of the economic impact of flood events in urban areas have traditionally focused locally on the initial estimates on the cost of lost assets, referred to as direct damage. These initial estimates are useful in establishing where capital and resources are needed for rebuilding post-event. However, since economies are interlinked geographically, there is a need establish how this direct damage cascades from the local economy throughout the wider economic systems at regional, national and global levels, thus determining the indirect damage. Quantified knowledge on flooding impact will be compiled, including the cost of direct damage and business interruption based on DEFRA's Multi-coloured Manual, into a set of damage functions at an urban area scale. A variant of the adaptive regional inputoutput (ARIO) model will then be developed to explore the vulnerabilities of urban area economies related to flood damage. This model enables direct damage to be determined using an event accounting matrix, consisting of a set of damage functions. The indirect damage is determined by integrating the local economic datasets and direct damage datasets based on supply constraint environmental input-output analysis. Using the variant ARIO model and output from agent based simulations, economic analyses can be performed regarding the impacts of flooding in a range of UK urban areas leading to specific economic vulnerabilities being identified, which should be the focus of increased preparedness. That is, the identification of business sectors beyond the immediate, or local, impact zone of a flood which are key to the wider economy at a regional and national level.

\subsection{Adaptive e-learning and behaviour change in organisations through the flood cycle}

This strand of research addresses the need to develop new ways of bridging knowledge gaps between outputs from agent based simulations and the promotion of real and timely behaviour change for resilience among the different stakeholders involved in business contingency planning for floods. As such, a key aspect of this strand is engagement with stakeholders such as businesses, emergency responders and emergency planners, local authorities and the Environment Agency. The development of the ABM mentioned earlier presents opportunities for improving the interface with a broad range of end-users and the tailoring of model outputs to the needs of diverse organisations. Feedback on iterative organisational learning and predicted behavioural changes, after using model outputs from single and/or multiple flood simulations as practical guidance, can then be embedded into the ongoing ABM design process and 
future simulations. This will improve the underlying assumptions in the modelling that determine the outputs. This research strand is also aimed at developing an e-learning intervention tool that uses new digital technologies to engage end-users with the practical guidance established, and evaluates their use for learning and behavioural change. As smart, future-oriented ubiquitous technologies will be dominant modes of future information engagement, design principles developed will be applicable across diverse flood modelling settings.

\section{Conclusions and future work}

It is widely acknowledged that the effect of future floods in the UK is expected to be significant in terms of damage, disruption and economic loss. Thus, the need to reduce the risk of flooding and its impact has been identified as key to mitigating this effect. The framework overview presented in this paper relates to ongoing research aimed at addressing the need to reduce the impact of flooding by improving organisations' response to and preparedness for floods in urban areas, reducing the disruption and economic loss associated with flooding, and strengthening the flood resilience of the wider economy and society.

Agent based modelling and simulation coupled with flood modelling provides a means of identifying organisations affected by a flood event in an urban area, investigating the actions and interactions of organisations in terms of their response and preparedness to flood events, and evaluate the implications of strategic policy decisions in the context of changes in behaviour. Key to such an agent based approach is the need to determine and codify how businesses respond to and prepare for flooding at an operational level. Engagement with a variety of businesses will establish the business continuity processes and dynamic behaviours of organisations in flood response and preparedness thus providing data inputs to an ABM. Subsequently, agent based simulations will identify key drivers and barriers to enhance organisational resilience through continuity planning. These simulations will enable the direct and indirect economic impact propagated at a local, regional and national level to be evaluated, leading to improvements in preparedness based on vulnerabilities identified. Further, simulations will facilitate the development of practical guidance to inform enhancements and adaptation in all stakeholders' response and preparedness in the face of flood events, which will be communicated to relevant organisations and communities via relevant risk communication and pedagogical concepts.

\section{Acknowledgement}

The authors gratefully acknowledge the funding provided by the UK's EPSRC under grant EP/K012770/1. 


\section{References}

[1] Beck, U., Risk Society: Towards a New Modernity, Sage Publications Ltd: London, 1992.

[2] Beck, U., World at Risk, Polity Press: Cambridge, 2009.

[3] Hood, C., James, O. \& Scott, C., Regulation of government: has it increased, is it increasing, should it be diminished?. Public Administration, 78(2), pp. 283-304, 2000.

[4] Stern, N., Stern Review on the Economics of Climate Change, HM Treasury / Cabinet Office, 2006.

[5] Pitt, M., The Pitt Review: Lessons learned from the 2007 floods, Cabinet Office, 2008.

[6] UK Climate Impacts Programme (UKCIP), A changing climate for business, UKCIP: Oxford, 2010.

[7] The Confederation of British Industry (CBI), Future Proof: preparing your business for a changing climate, CBI: London, 2009.

[8] Foresight: Future Flooding, Foresight: Future Flooding Study, Flood and Coastal Defence Project: Office of Science and Technology, 2004.

[9] HM Government, A Strong Britain in an Age of Uncertainty: The National Security Strategy, HM Government, 2010.

[10] Walker, C. \& Broderick, J., The Civil Contingencies Act 2004: Risk, Resilience and the Law in the United Kingdom, Oxford University Press, 2006.

[11] Institution of Civil Engineers (ICE), Flooding: Engineering resilience, ICE: London, 2008.

[12] Civil Contingencies Act 2004, Act of Parliament of the United Kingdom, 2004.

[13] British Standards Institution (BSI), ISO 22301 Business Continuity Management, BSI: London, 2012.

[14] Elliott, D., Herbane, B. \& Swartz, E., Business Continuity Management, Routledge: London, 2001.

[15] Herbane, B., The evolution of business continuity management: A historical review of practices and drivers, Business History, 52(6), pp. 978$1002,2010$.

[16] Musgrave, B. \& Woodman, P., Weathering the Storm: The 2013 Business Continuity Management Survey, Chartered Management Institute: London, 2013.

[17] Herbane, B., Small business research: Time for a crisis-based view, International Small Business Journal, 28(1), pp. 43-64, 2010.

[18] Bellamine-Ben Saoud, N., Ben Mena, T., Dugdale, J., Pavard, B. \& Ben Ahmed, M., Assessing large scale emergency rescue plans: an agent based approach, International Journal of Intelligent Control and Systems: Special Issue on Emergency Management Systems, 11(4), pp. 260-271, 2006.

[19] Hawe, G.I., Wilson, D.T., Coates, G. \& Crouch, R.S., Investigating the Effect of Overtriage on Hospital Arrival Times of Critically Injured Casualties during a Major Incident using Agent-Based Simulation, In Proc. 
of the 6th International Conference on Soft Computing and Intelligent Systems and the 13th International Symposium on Advanced Intelligent Systems, Kobe, Japan, 2012.

[20] Liu, Y., Okada, N., Shen, D. \& Li, S., Agent based flood evacuation simulation of life-threatening conditions using Vitae system model, Journal of Natural Disaster Science, 31(2), pp. 33-41, 2009.

[21] Dawson, R., Peppe, R. \& Wang, M., An agent based model for risk-based flood incident management, Natural Hazards, 59(1), pp. 167-189, 2011.

[22] Hunter, N.M., Bates, P.D., Neelz, S., Pender, G., Villanueva, I., Wright, N.G., Liang, D., Falconer, R.A., Lin, B., Waller, S., Crossley, A.J. \& Mason, D.C., Benchmarking 2D hydraulic models for urban flood simulations, Proceedings of the Institution of Civil Engineers: Water Management, 161(1), pp. 13-30, 2008.

[23] Neal, J.C., Bates, P.D., Fewtrell, T.J., Hunter, N.M., Wilson, M.D. \& Horritt, M.S., Distributed whole city water level measurements from the Carlisle 2005 urban flood event and comparison with hydraulic model simulations, Journal of Hydrology, 368, pp. 42-55, 2009.

[24] McMillan, H.K. \& Brasington, J., End-to-end flood risk assessment: A coupled model cascade with uncertainty estimation, Water Resources Research, 44(3), W03419, 2008. 